\title{
Teaching facial fracture repair: A novel method of surgical skills training using three-dimensional biomodels
}

\author{
Neil D'Souza BSc MHSc ${ }^{1}$, James Mainprize PhD², Glenn Edwards B Arch M Arch², \\ Paul Binhammer MSc, $\mathrm{MD}^{2,3}$, Oleh Antonyshyn $\mathrm{MD}^{2,3}$
}

\begin{abstract}
N D'Souza, J Mainprize, G Edwards, P Binhammer, O Antonyshyn. Teaching facial fracture repair: A novel method of surgical skills training using threedimensional biomodels. Plast Surg 2015;23(2):81-86.
\end{abstract}

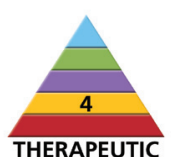

BACKGROUND: The facial fracture biomodel is a three-dimensional physical prototype of an actual facial fracture. The biomodel can be used as a novel teaching tool to facilitate technical skills training in fracture reduction and fixation, but more importantly, can help develop diagnostic and management competence.

OBJECTIVE: To introduce the 'facial fracture biomodel' as a teaching aid, and to provide preliminary evidence of its effectiveness in teaching residents the principles of panfacial fracture repair.

METHODS: Computer three-dimensional image processing and rapid prototyping were used to generate an accurate physical model of a panfacial fracture, mounted in a silicon 'soft tissue' base. Senior plastic surgery residents in their third, fourth and fifth years of training across Canada were invited to participate in a workshop using this biomodel to simulate panfacial fracture repair. A short didactic presentation outlining the 'patient's' clinical and radiological findings, and key principles of fracture repair, was given by a consultant plastic surgeon before the exercise. The residents completed a pre- and postbiomodel questionnaire soliciting information regarding background, diagnosis and management, and feedback.

RESULTS: A total of 29 residents completed both pre- and postbiomodel questionnaires. Statistically significant results were found in the following areas: diagnosis of all fracture patterns $\left(P=8.2 \times 10^{-7}[t\right.$ test $\left.]\right)$, choice of incisions for adequate exposure $(\mathrm{P}=0.04$ [ $t$ test $])$ and identifying sequence of repair $\left(\mathrm{P}=0.019\left[\chi^{2}\right.\right.$ test $\left.]\right)$. Subjective evaluation of workshop effectiveness revealed a statistically significant increase in 'comfort level' only among third year trainees. Overall, positive feedback was reported among all participants.

CONCLUSIONS: Biomodelling is a promising ancillary teaching aid that can assist in teaching residents technical skills, as well as how to assess and plan surgical repair.

Key Words: 3D biomodel; Facial fracture repair; Plastic surgery; Surgical education

\section{L'enseignement de la réparation des fractures au visage : une nouvelle méthode d'enseignement des habiletés chirurgicales à l'aide de biomodèles tridimensionnels}

HISTORIQUE : Le biomodèle de fracture au visage est un prototype physique tridimensionnel de véritable fracture au visage. Il peut être utilisé comme outil d'enseignement novateur pour faciliter l'enseignement des habiletés techniques afin de réduire et fixer les fractures, mais surtout, pour acquérir des compétences de diagnostic et de prise en charge.

OBJECTIF : Présenter le «biomodèle de fracture au visage » comme aide à l'enseignement et fournir des données préliminaires de son efficacité à enseigner aux résidents les principes de la réparation des fractures panfaciales. MÉTHODOLOGIE : Le traitement informatique d'images tridimensionnelles et le prototypage rapide ont été utilisés pour générer un modèle physique précis de fracture panfaciale, monté sur une base de « tissus mous » de silicone. Les résidents seniors en chirurgie plastique de troisième, quatrième et cinquième années du Canada ont été invités à participer à un atelier au moyen de ce biomodèle pour simuler la réparation d'une fracture panfaciale. Avant l'exercice, un plasticien consultant a fait une courte présentation didactique soulignant les observations cliniques et radiologiques du « patient » et les principaux principes de la réparation de la fracture. Les résidents ont rempli un questionnaire avant et après avoir utilisé le biomodèle, contenant leurs commentaires et de l'information sur l'expérience, le diagnostic et la prise en charge.

RÉSULTATS : Au total, 29 résidents ont rempli le questionnaire avant et après le biomodèle. Des résultats statistiquement significatifs ont été constatés dans les secteurs suivants : diagnostic de tous les profils de fracture $\left(\mathrm{P}=8,2 \times 10^{-7}\right.$ [test $\left.\left.t\right]\right)$, choix d'incisions pour une exposition adéquate $(\mathrm{P}=0,04$ [test $t])$ et détermination de la séquence de réparation $\left(\mathrm{P}=0,019\right.$ [test $\left.\left.\chi^{2}\right]\right)$. D'après l'évaluation subjective de l'efficacité de l'atelier, seuls les résidents de troisième année présentaient une augmentation statistiquement significative du « niveau de confort ». Dans l'ensemble, tous les participants ont fait des commentaires positifs.

CONCLUSIONS : Le biomodélisation est une aide auxiliaire à l'enseignement prometteuse qui peut contribuer à enseigner aux résidents les habiletés techniques, de même que l'évaluation et la planification des réparations chirurgicales.

rapid feedback (computers) (7). However, there are significant disadvantages such as cost (animals, cadavers, computers), lack of multiple use (cadavers, animals, bench models), anatomical differences (animals) and lack of 'realism' (computers) (7). Optimizing the advantages and disadvantages of such previous surgical learning methods has prompted the American College of Surgeons recommendation of integrating computers, virtual reality and simulation for surgery education (7).

The use of biomodels is currently one of the most practical means of surgical simulation. Biomodels are three-dimensional (3D) solid representations of anatomical structures. The use of these models to simulate spinal and cerebrovascular procedures have previously been evaluated and found to be very effective (7).

Craniofacial fracture skills laboratories frequently use facial bone models to teach basic technical skills. The focus is on teaching trainees 


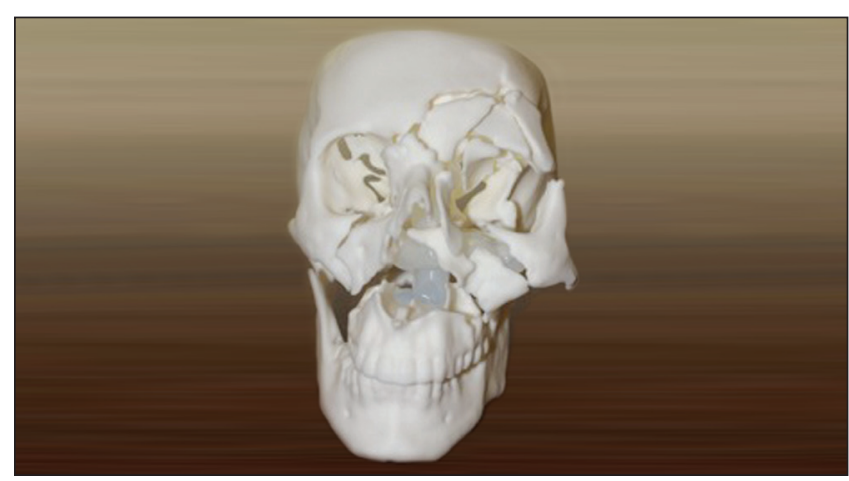

Figure 1) Patient-specific facial fracture biomodel

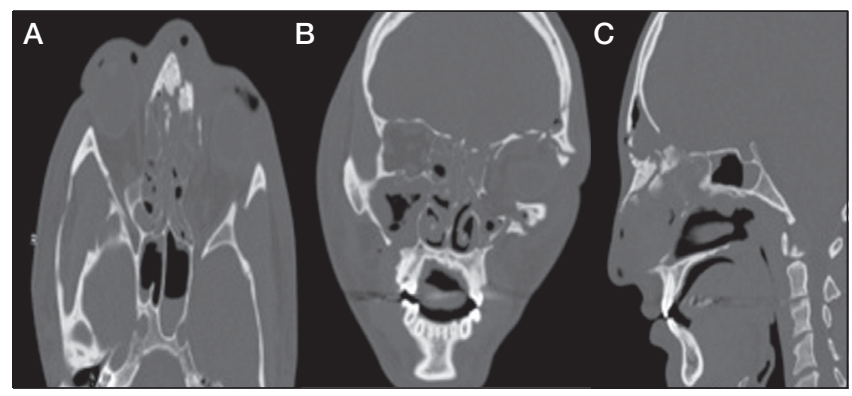

Figure 2) Pateint relevant axial (A), coronal (B) and sagittal (C) computed tomography slices

how to adapt a fixation plate and apply screws to fix a simple fracture line. The simplest fracture models are, therefore, used for this specific purpose.

However, competency in facial fracture management requires far more than technical proficiency in fracture reduction and the adaptation of appropriate fixation devices. Competency requires clinical and radiological diagnostic ability, proficiency in treatment planning and in the sequencing of fracture repair, and the ability to anticipate the degree of instability and the potential need for wider exposures or bone graft. These crucial skills are not addressed in current surgical skills training.

We have developed a practical hands-on facial fracture training module that is specifically designed to teach and test these skills in surgical residents. The purpose of the present study was to: introduce the 'facial fracture biomodel' as an aid in comprehensive teaching of panfacial fracture repair; and to provide preliminary evidence of its effectiveness in teaching residents

\section{Biomodel creation}

\section{METHODS}

A trauma patient with unstable panfacial fractures was selected from the Trauma Database at Sunnybrook Health Sciences Centre (Toronto, Ontario). Based on the preoperative computed tomography (CT) image data, computer image processing and 3D modelling was used to generate a virtual 3D model of the patient's facial fractures. The 3D CT images did not reveal undisplaced fractures or the extent of the orbital fractures. These features were more accurately revealed in the selected coronal and axial CT scans (ie, the axial and coronal images that revealed all fracture lines and would be sufficient to diagnose the fracture pattern were specifically chosen by the senior author $[\mathrm{OA}]$ ).

The CT image data were then exported for rapid prototyping to generate a realistic patient-specific facial fracture biomodel (Calavera Surgical Design, USA) (8). The biomodel featured articulated temporomandibular joints and multiple fracture segments embedded in a 'soft tissue' silicone core to simulate the soft tissue envelope. The fracture patterns were specifically created in the physical skull model (ie, blow-out fractures were modelled as a defect, and minimally displaced fractures were modelled as an unstable fracture line, to facilitate
TABLE 1

Rank order sequence of repair steps

\section{Craniofrontal}

Maxillomandibular fixation

Orbitozygomatic complex

Nose

Naso-orbital ethmoid

Maxillary buttresses

Seat condylar heads and autorotate mandible

accurate intraoperative diagnosis and decision making). The entire construct was rigidly mounted to a work bench (Figure 1).

\section{Study population}

The study population consisted of consenting plastic surgery residents, enrolled in plastic surgery resident training programs across Canada. The teaching exercise was restricted to senior residents, in their third, fourth or fifth year of training.

\section{Setting}

The Surgical Skills Centre at Mount Sinai Hospital (Toronto, Onatrio) is a teaching facility associated with the Department of Surgery at the University of Toronto (Toronto, Ontario). McCrae et al (9) detail the particulars of this centre, which provided the surgical learning environment for performing this facial fracture repair simulation.

\section{Sequence of events during the workshop}

Presimulation didactic session: A short teaching session outlining key principles of panfacial fracture was given by a staff plastic surgeon (OA) before the simulation exercise. Workshop objectives and key teaching principles were outlined.

Case presentation: The history and clinical findings were presented. Multiple relevant axial, coronal and sagittal CT slices were presented as a repeating sequence of images (Figure 2). All patient-identifying data were removed.

Prebiomodel questionnaire: A test was completed by each of the residents before having the opportunity to actually view the fracture biomodel. Thus, the answers they provided were based entirely on their ability to interpret the clinical and radiological findings to diagnose the fracture pattern and formulate a treatment plan. They were not provided with the correct answers to the test at any point during the workshop.

Questions solicited the following information:

1. Background

- level of residency training

- number of fracture repairs assisted on

2. Surgical case diagnosis and management

- identify pattern of facial fractures from a list of 24 possibilities

- indicate necessity for craniotomy (yes/no)

- indicate incisions needed to expose the fracture from list of seven possibilities

- indicate necessity and type of primary bone grafting

- rank sequence of seven repair steps (Table 1)

3. Comfort level with treating panfacial fracture according to level of residency training

4. Benefit derived from workshop by asking:

- How effective was this workshop in teaching you the surgical skills required in treating facial fractures?

- Was the skull biomodel of value in teaching you the surgical skills required in treating facial fractures?

Simulated craniofacial repair with 3D biomodel

Residents were paired and each pair was given one skull biomodel to perform the relevant tasks necessary to repair the craniofacial fractures. 
TABLE 2

Surgical case diagnosis and management $(n=29)$

\begin{tabular}{lcccc}
\hline & \multicolumn{3}{c}{ Correct, \%, mean } & \\
\cline { 2 - 4 } & $\begin{array}{c}\text { Pre- } \\
\text { workshop }\end{array}$ & $\begin{array}{c}\text { Post- } \\
\text { workshop }\end{array}$ & $\begin{array}{c}\text { Difference } \\
\text { (Post-Pre) }\end{array}$ & P $^{*}$ \\
\hline $\begin{array}{l}\text { Diagnosis of all } \\
\text { fracture patterns }\end{array}$ & 58.4 & 78.9 & 20.5 & $\mathbf{8 . 2 \times 1 0 ^ { - 7 }}$ \\
$\begin{array}{c}\text { Choice of incisions for } \\
\text { adequate exposure }\end{array}$ & 68.5 & 79.4 & 10.9 & $\mathbf{0 . 0 4}$ \\
\hline
\end{tabular}

${ }^{*} t$ test (statistically significant at $\alpha=0.05$ [bold])

TABLE 3

Surgical case diagnosis and management $(n=29)$

\begin{tabular}{|c|c|c|c|c|c|}
\hline & \multicolumn{2}{|c|}{ Preworkshop } & \multicolumn{2}{|c|}{ Postworkshop } & \multirow[b]{2}{*}{$\mathbf{P}^{*}$} \\
\hline & Correct & Incorrect & Correct & Incorrect & \\
\hline Is craniotomy required? & 18 & 11 & 24 & 5 & 0.078 \\
\hline $\begin{array}{l}\text { How should patient be } \\
\text { intubated? }\end{array}$ & 17 & 12 & 21 & 8 & 0.269 \\
\hline $\begin{array}{l}\text { Is the use of a primary } \\
\text { bone graft required? }\end{array}$ & 17 & 12 & 13 & 16 & 0.293 \\
\hline $\begin{array}{l}\text { Identify sequence } \\
\text { of repair }\end{array}$ & 2 & 27 & 9 & 20 & 0.019 \\
\hline
\end{tabular}

Data presented as $n$ unless otherwise indicated. ${ }^{*} \chi^{2}$ test (statistically significant at $\alpha=0.05$ [bold])

Within each pair, the residents shared the responsibilities of surgeon and surgical assistant. No instructions were given on how to manage the panfacial fracture; it was an entirely experiential learning experience. In total, $2.5 \mathrm{~h}$ were allotted to complete the simulation.

\section{Postbiomodel questionnaire}

The same questionnaire as the prebiomodel one was then administered at the conclusion of the practical exercise.

Results were compared with an ideal manner in which to achieve the panfacial fracture repair for the simulation model and clinical scenario as devised by the staff plastic surgeon (OA). Statistical analyses were completed using Excel (Microsoft Corporation, USA).

\section{RESULTS}

Participant demographics

There were a total of 34 participants, of whom 29 completed both preand postworkshop tests. As such, analyses were completed for these participants $(n=29)$.

The level of previous clinical experience was variable. The study group comprised 15 third-year residents (R3), 11 fourth-year residents (R4), and three fifth-year residents (R5). While all R5 residents had reported assisting in $>15$ facial fracture cases during the course of their training, the vast majority of participants $(n=18)$ had been involved in $<10$ cases (Figure 3 ).

Efficacy of fracture biomodel

The efficacy of the fracture biomodel as a teaching tool in educating surgical residents was evaluated objectively by administering a quiz before and following the practical skills session.

The ability to diagnose the facial fracture pattern correctly increased significantly following the fracture biomodel workshop. Only $58 \%$ of residents diagnosed the fracture pattern correctly on the basis of clinical presentation and radiological findings. The ability to view the fractures directly in a fracture model improved the diagnostic ability significantly.

The ability to make appropriate clinical decisions regarding the incisions to be used for exposure, the need for craniotomy and the management of the airway were all improved following the practical exercise.

The greatest degree of uncertainty was identified in two areas. First, primary bone grafting in facial trauma was a confusing issue, with
TABLE 4

\begin{tabular}{|c|c|c|}
\hline Sequence & Frequency & $\%$ Correct \\
\hline $\begin{array}{l}\text { Craniofacial } \\
\text { Nasoorbital ethmoid } \\
\text { Maxillomandibular fixation } \\
\text { Nose } \\
\text { Orbitozygomatic complex } \\
\text { Seat condylar heads and autorotate mandible } \\
\text { Maxillary butresses }\end{array}$ & 2 & $100(7 / 7)$ \\
\hline $\begin{array}{l}\text { Maxillary buttresses } \\
\text { Maxillomandibular fixation } \\
\text { Nose } \\
\text { Seat condylar heads and auto-rotate mandible } \\
\text { Nasoorbital ethmoid } \\
\text { Orbitozygomatic complex } \\
\text { Craniofacial }\end{array}$ & 2 & $0(0 / 7)$ \\
\hline
\end{tabular}

TABLE 5

\section{Sequence of repair - top three common sequences postworkshop}

\begin{tabular}{lcc}
\hline Sequence & $\begin{array}{c}\text { \% Correct } \\
\text { (correct steps } \\
\text { indicated/actual } \\
\text { correct steps) }\end{array}$ \\
\hline $\begin{array}{l}\text { Craniofacial } \\
\text { Nasoorbital ethmoid }\end{array}$ & 9 & $100(7 / 7)$ \\
Maxillomandibular fixation & & \\
Nose & & \\
Orbitozygomatic complex & & \\
Seat condylar heads and autorotate mandible & & \\
Maxillary butresses & & \\
Craniofacial & & \\
Maxillary buttresses & & \\
Maxillomandibular fixation & & \\
Nose & & \\
Orbitozygomatic complex & & \\
Seat condylar heads and autorotate mandible & & \\
Nasoorbital ethmoid & & \\
Craniofacial & & \\
Nose & & \\
Maxillomandibular fixation & \\
Seat condylar heads and auto-rotate mandible & \\
Orbitozygomatic complex & \\
Maxillary buttresses & \\
Nasoorbital ethmoid & & \\
\hline
\end{tabular}

almost one-half of the respondents not recognizing the need for primary grafting. The fracture biomodel was not effective in demonstrating this need. Second, the sequence of repair was also highly variable.

Surgical case diagnosis and management

While there were changes in comfort level with treating panfacial fracture before and after the workshop across all levels of residency training, statistical analyses using the Mann-Whitney $U$ test indicated a statistically significant difference in comfort level treating panfacial fractures for R3 trainees. There was no statistically significant difference for comfort level for R4 trainees, nor was there any difference between R3 versus R4 with regard to comfort level. No statistical analyses could be performed involving $\mathrm{R} 5$ trainees because there were only two participants who provided complete responses for both pre- and postworkshop quizzes. (Tables 2 to 5) (Figures 4, 5 and 6). 


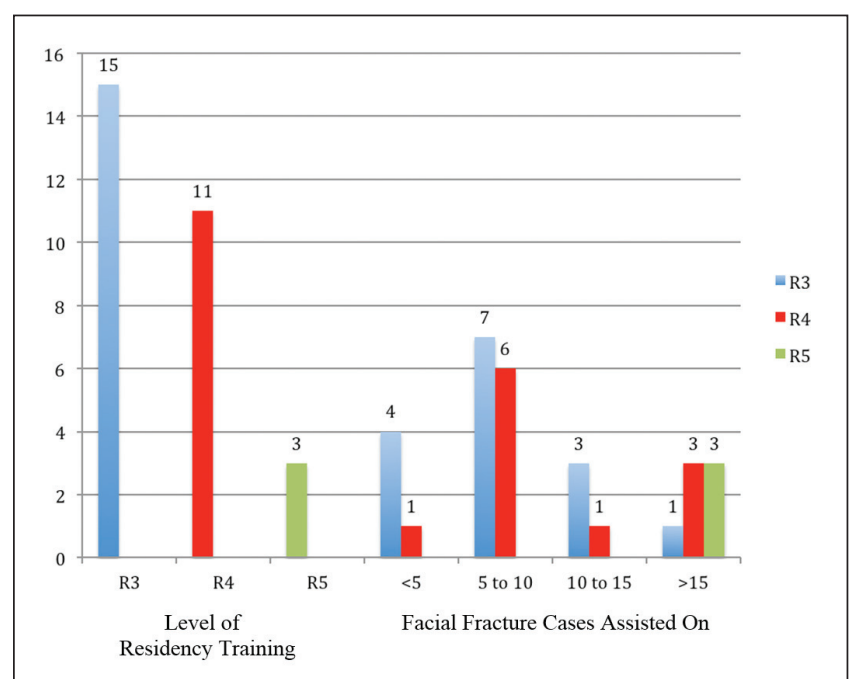

Figure 3) Facial fracture surgical assisting based on resident training level. R3 Third-year resident; R4 Fourth-year resident; R5 Fifth-year resident

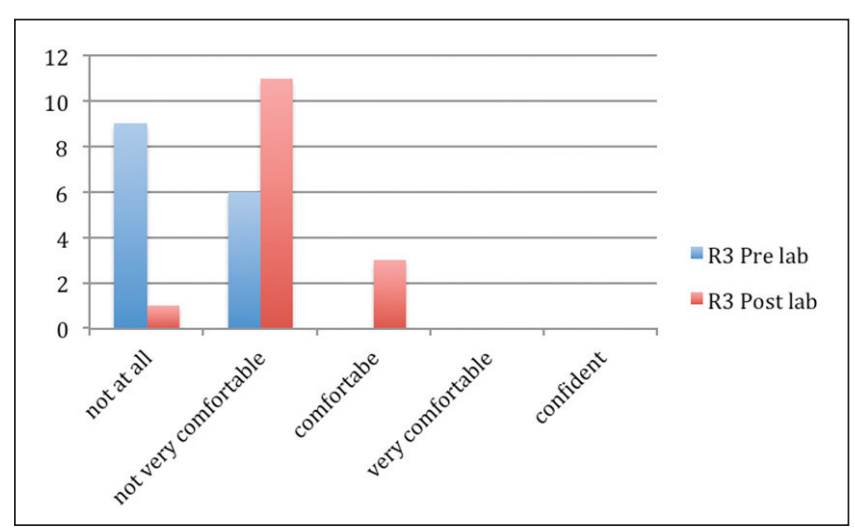

Figure 4) Comfort level in treating panfacial fracture according to level of residency training. *Statistically significant. Lab Laboratory; R3 Thirdyear resident

\section{Biomodel}

The practical exercise provided residents with an opportunity to completely repair a panfacial fracture. The sequence of repair, method of reduction and choice of fixation device was left to the resident. Sample results are illustrated in Figures 7 and 8.

\section{Efficacy of fracture biomodel: subjective}

The effectiveness of the fracture biomodel in teaching facial fracture repair was further evaluated by a postworkshop questionnaire.

\section{Benefit derived (postworkshop evaluation): comparison according} to level of residency training:

1. How effective was this workshop in teaching you the surgical skills required in treating facial fractures? Twenty-two of 29 residents rated the workshop as extremely effective (Figure 9).

2. Was the skull biomodel of value in teaching you the surgical skills required in treating facial fractures? Twenty-one of 29 residents found the skull biomodel to be extremely effective, while five found it to be moderately effective (Figure 10).

\section{DISCUSSION}

Simulation is used in surgical training programs to teach residents how to assess, plan and repair routine and complex patient presentations. While plastic surgery residency programs have not adopted the paradigm to the same degree as general surgery, several simulation models specific to plastic surgery have emerged to advance the contribution of

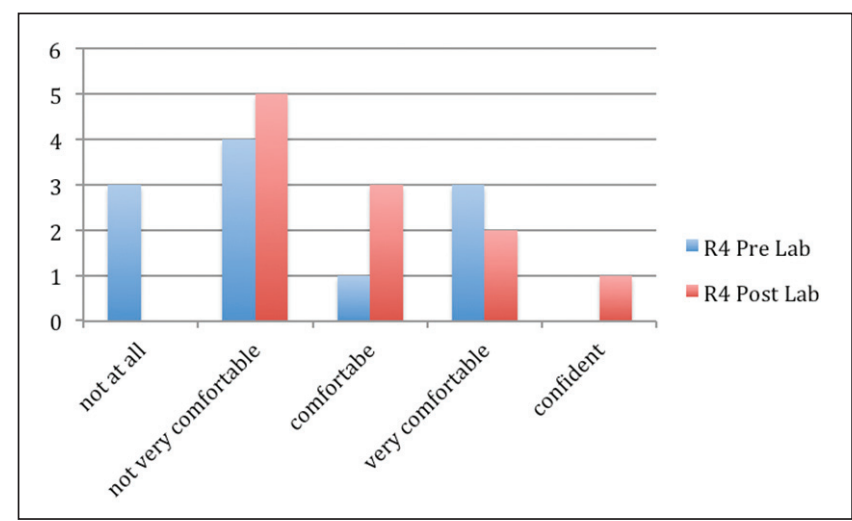

Figure 5) Comfort level in treating panfacial fracture according to level of residency training (no statistically significant difference). Lab Laboratory; R4 Fourth-year resident

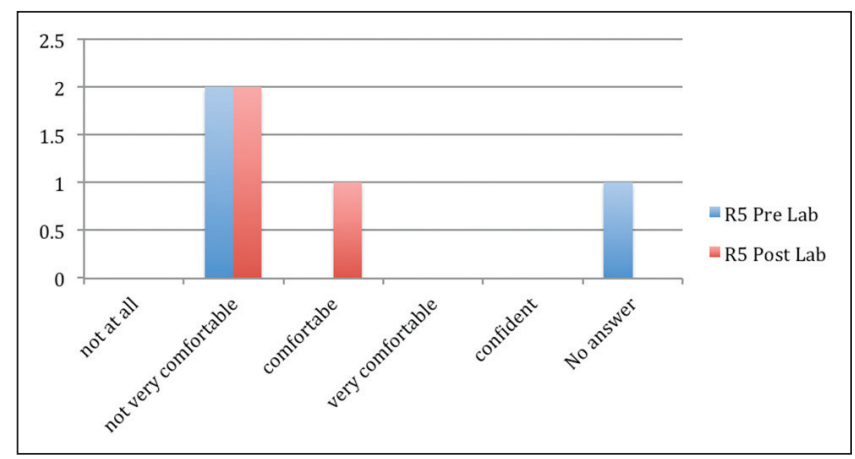

Figure 6) Comfort level in treating panfacial fracture according to level of residency training (no statistically significant difference). Lab Laboratory; R5 Fifth-year resident

this technique to surgical education. We have demonstrated the feasibility of creating a biomodel that accurately reflects real-life patient clinical and radiological findings. Furthermore, this biomodel provided the means by which several surgical teaching principles could be performed: manipulation and reduction of fracture segments; drilling of bone and screws; and plate fixation. In addition, the biomodel approach facilitates the teaching of the technical aspects of fracture reduction and fixation, and sequencing of fracture repair in panfacial fractures. Finally, the model allows plastic surgery residents to practice CT-based diagnosis and treatment plan design and implementation.

As a surgical teaching tool, our biomodel approach to panfacial fracture repair was an exercise in experiential learning. We demonstrated it to be preliminarily effective in aiding resident ability to identify and diagnose pattern recognition-type problems. We found a statistically significant improvement in the diagnosis of fractures, choice of incisions for adequate exposure and sequence of repair. The improvement in identifying the repair sequence was further demonstrated given the most common sequence pre- and postworkshop; while two residents correctly identified the entire sequence before the workshop, nine correctly did so thereafter. Further, an additional four residents had $71 \%$ of the sequence correct. Similar findings have also been observed in a study involving orthopedic surgery residents, in which $3 \mathrm{D}$ anatomical teaching models improved the ability to identify acetabular fracture patterns (10).

Although our biomodel was able to improve resident ability to diagnose and identify pattern recognition-type problems, there was no improvement for decision making of a binary (yes/no) type nature. Specifically, there was no statistically significant difference pre-versus postworkshop in resident ability to recognize the need for craniotomy, the ability to determine the method of intubation and the use of primary bone graft. Given that the biomodel presents fractures directly to 


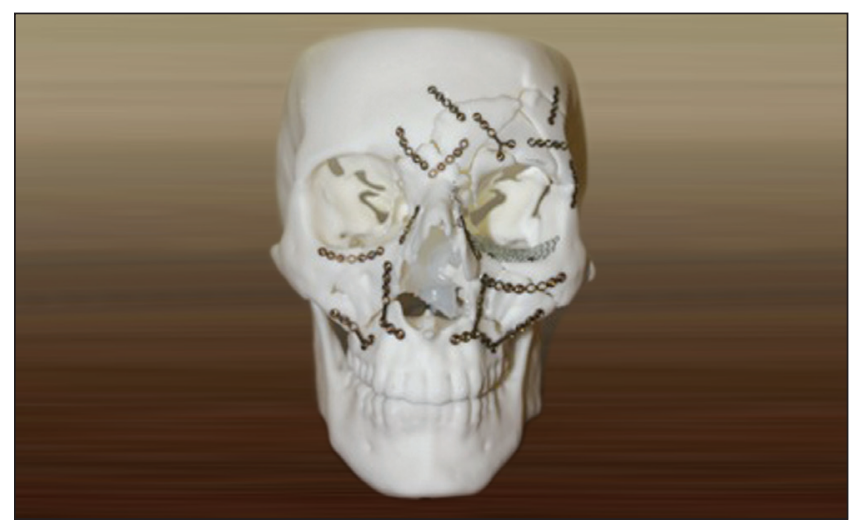

Figure 7) Resident-repaired panfacial fracture

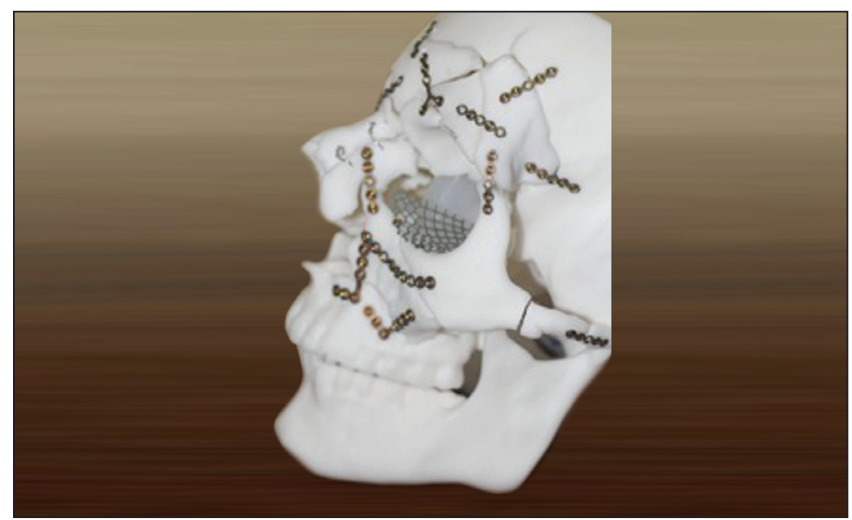

Figure 8) Resident-repaired panfacial fracture - lateral

residents, a more tangible representation of pattern repair can be visualized. However, making a decision regarding the need for craniotomy, for instance, may not be as readily apparent. In other words, perhaps these findings may be the result of knowledge deficit regarding the indications for such interventions, or it may not be immediately intuitive to the residents in the context of the biomodel and clinical scenario.

With regard to resident 'comfort level', only R3 trainees were observed to have a significant gain. However, this increase in 'comfort level' was reflected in more responses in the 'not very comfortable' and 'comfortable' categories postworkshop. The degree to which this improved 'comfort level' can translate clinically is unknown. Although the raw data showed a change, there was no statistically significant difference observed for R4 trainees with regard to 'comfort level' and value of biomodel in teaching skills required for facial fracture. A similar result was observed for R5 trainees. However, in both instances, these results may be due smaller sample sizes (ie, $n=11$ for $R 4$; $n=3$ for $R 5$ ). Despite these results, participant comments, as a whole, were overwhelmingly positive of the workshop. Minor points for improvement included: less silicone (which occasionally interfered with fracture reduction); more discussion about incisions; and a one-page handout summarizing salient points.

\section{Study limitations}

One study limitation was the small test population, which was further fragmented by the varied exposure to facial fractures and level of training. Another limitation was the lack of assessment of long-term retention or educational benefit postworkshop. Finally, 3D CT scans can affect a novice's ability to diagnose or recognize a fracture pattern; however, this was not shown in the premodel test.

\section{Future directions}

Given there were unequal numbers of resident participants, particularly R5 trainees, a logical next step would be to optimize the participants in

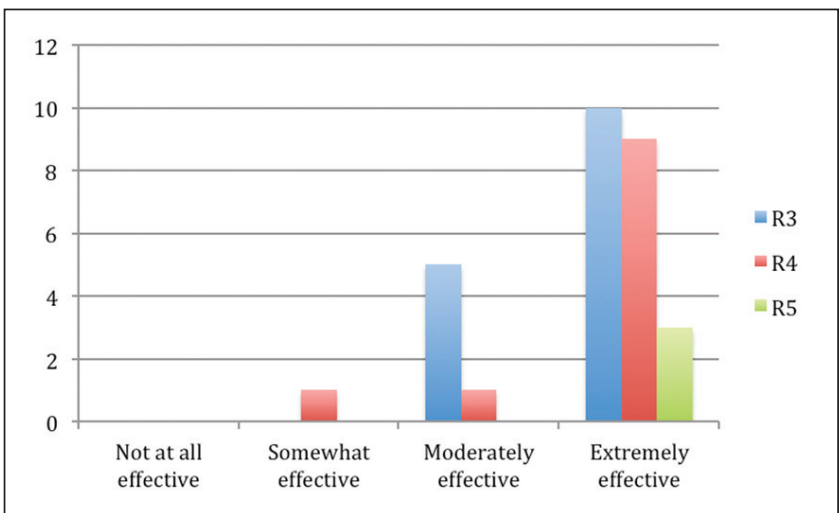

Figure 9) Effectiveness of the workshop. No statistically significant difference among ratings or year of residence (Mann-Whitney $U$ test). R3 Thirdyear resident; $R 4$ Fourth-year resident; $R 5$ Fifth-year resident

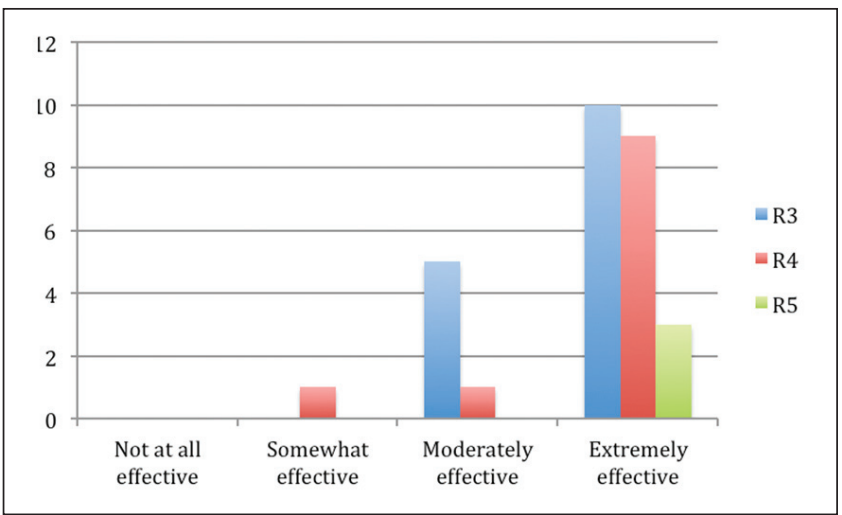

Figure 10) Effectiveness of skull biomodel in teaching surgical skills. No statistically significant difference among ratings or year of residence (MannWhitney $U$ test). R3 Third-year resident; R4 Fourth-year resident; R5 Fifth-year resident

future workshops. In addition, further examination is required to assess the degree to which the biomodel and case scenario can facilitate decision making regarding craniotomy, intubation and use of primary bone graft; either the clinical scenario can be altered to enable such decision making, or less emphasis can be placed on this aspect of the workshop and be covered in the postsimulation didactic session. Examination of long-term retention would also be valuable in further experiential learning with the fracture biomodel. Finally, improvements can be made addressing the above workshop feedback.

We believe the 3D biomodel to be a useful ancillary teaching model. It may be an effective tool to test candidates' abilities to formulate and execute a surgical procedure by testing knowledge, the ability to apply that knowledge in a clinical scenario, as well as technical ability.

\section{CONCLUSION}

We have demonstrated feasibility of using 3D data from a real patient CT scan to create a biomodel replicating a panfacial fracture. Furthermore, we have shown preliminary evidence of its effectiveness in teaching plastic surgery residents how to assess, plan and repair these complex fractures. Our biomodel approach significantly improved pattern recognition-type fracture repair. However, there was no improvement in more binary type decision making during the fracture repair simulation. Overall, only R3 trainees 'comfort level' improved as a result of this exercise. However, participant feedback was positive overall. Given the unequal number of participants, future workshops will endeavour to optimize trainees and modify accordingly to address the decision-making objectives of the simulation and participant feedback. 


\section{REFERENCES}

1. Reznick RK, MacRae H. Teaching surgical skills - changes in the wind. N Engl J Med 2006;355:2664-9.

2. Council Directive 93/104/EC. Official Journal of the European Communities 1993;L307:18-24.

3. Leach DC. A model for GME: Shifting from process to outcomes a progress report from the Accreditation Council for Graduate Medical Education. Med Educ 2004;38:12-4.

4. Tavakol M, Ali Mohaghegi M, Dennick R. Assessing the skills of surgical residents using simulation. J Surg Education 2008:65:77-83.

5. Rosen JM, Long SA, McGrath DM, Greer SE. Simulation in plastic surgery training and education: The path forward. Plast Reconstr Surg 2009:123:729-38.

6. D'Urso PS, Williamson O, Thompson R. Biomodelling as an aid to spinal instrumentation. Spine 2005;30:2841-5.
7. Wurm G, Lehner M, Tomancok B et al. Cerebrovascular biomodelling for aneurysm surgery: Simulation-based training by means of rapid prototyping techniques. Surg Innov 2011;18:294-306.

8. Calavera Surgical Design. About Calavera. <www. calaverasurgicaldesign.com/Technology_Product.htm> (Accessed March 21, 2013).

9. McCrae HM, Satterthwaite L, Reznick RK. Setting up a surgical skills centre. World J Surg 2008;32:189-98.

10. Hansen E, Marmor M, Matityahu A. Impact of a three-dimensional "hands-on" anatomic teaching module on acetabular fracture pattern recognition by orthopaedic residents.

J Bone Joint Surg Am 2012:94:e177, 1-7. 